Article

\title{
Effects of Pure and Mixed Autochthonous Torulaspora delbrueckii and Saccharomyces cerevisiae on Fermentation and Volatile Compounds of Narince Wines
}

\author{
Ebru Arslan ${ }^{1}$, Zeynep Dilan Çelik ${ }^{1,2}$ and Turgut Cabaroğlu ${ }^{1, *}$ \\ 1 Department of Food Engineering, Faculty of Agriculture, Çukurova University, 01330 Adana, Turkey; \\ ebru.arslann02@gmail.com (E.A.); z.d.celik@gmail.com (Z.D.Ç.) \\ 2 Department of Biotechnology, Institute of Natural and Applied Science, Cukurova University, \\ 01330 Adana, Turkey \\ * Correspondence: tcabar@cu.edu.tr; Tel.: +90-322-338-6997; Fax: +90-322-338-6614
}

Received: 11 July 2018; Accepted: 30 August 2018; Published: 5 September 2018

\begin{abstract}
The cultivar of Narince is a native white grape variety of Vitis vinifera, grown in Tokat city, the Mid-Black Sea Region of Anatolia. In this study, the effects of pure and mixed autochthonous Torulaspora delbrueckii-214 and Saccharomyces cerevisiae-1088 cultures on the fermentation behavior and aroma compounds of Narince wines were investigated. Volatile compounds formed in wines were extracted using a liquid-liquid extraction method and determined by GC-MS-FID. Narince grape must was fermented in duplicate, under the following three conditions. Two pure cultures of T. delbrueckii-214 and S. cerevisiae-1088 and a mixture of T. delbrueckii-214 and S. cerevisiae-1088 (1:1). The presence of the non-Saccharomyces T. delbrueckii-214 yeast slowed down the fermentation and produced a lower level of ethanol and a higher levels of glycerol and volatile acid. Only the pure culture of T. delbrueckii-214 was unable to finish fermentation. On the other hand, mixed culture fermentation improved the aroma intensity and complexity of wine due to increased levels of higher alcohols and esters. According to sensory analysis, wine fermented with mixed culture was the most preferred wine followed by wine inoculated with pure S. cerevisiae-1088. This study confirms the role of T. delbrueckii in wine aroma and the potential of non-Saccharomyces use in winemaking.
\end{abstract}

Keywords: Saccharomyces cerevisiae; Torulaspora delbrueckii; Narince; autochthonous; mixed culture

\section{Introduction}

The fermentation of grape juice into wine is a complex microbial process carried out by yeasts belonging to different species of Saccharomyces and non-Saccharomyces yeasts [1-3]. In modern winemaking, alcoholic fermentation is typically carried out using selected strains (microbial starter) of S. cerevisiae. However, during traditional fermentation of the grape must different yeast species/strains that are naturally present on the berries, grapes, or in the winery environment are involved into the fermentation [4]. The early stages of natural fermentation are dominated by non-Saccharomyces yeasts from the genera, Candida, Hanseniaspora, Torulaspora, and Pichia. These yeasts have low fermentation activity but compose multiple flavor compounds such as, esters, higher alcohols, terpenes, and glycerol [5]. After the first days of fermentation, strongly fermenting and ethanol tolerant species of S. cerevisiae become dominant and complete the wine fermentation [6,7]. Generally, non-Saccharomyces species are considered to be of secondary significance or undesirable during alcoholic fermentation. However, several authors have reported that the dominance of non-Saccharomyces yeasts during the early stages of fermentation have a major impact on the organoleptic quality of wines [8-10]. Also, 
mixed culture fermentations of several non-Saccharomyces species, such as, Hanseniaspora uvarum, T. delbrueckii, Kluyveromyces thermotolerans, and Pichia kluyveri, together with S. cerevisiae have been investigated during winemaking. The positive impact with mixed culture fermentation protocols stimulated the investigation and selection of new non-Saccharomyces starters able to carry out alcoholic fermentation together with S. cerevisiae $[9,11,12]$. T. delbrueckii is one of the non-Saccharomyces yeast species which is commercialized because of its positive impact on the organoleptic properties of wines [11]. However the use of T. delbrueckii pure culture leads to 'stuck' fermentation. It has been reported that mixed culture of selected strains of this species with $S$. cerevisiae modulate wine flavor and provide complete alcoholic fermentation [1]. Several authors have indicated that besides the reduction of off-flavors, compounds like acetaldehyde, and acetoin, the mixed inoculation of these two yeasts species gives a steady increase in 2-phenylethanol, terpenes, and lactones [1,11-13].

The yeast influence on wine aroma is not only species dependent but also strain dependent [4]. In recent years, there is increasing interest among wine-researchers and winemakers to select local strains with the aim to select starter cultures that are potentially well-adapted to a specific grape must reflecting the biodiversity of a given region, which supports the notion that specific autochthonous yeast strains can be associated with a terroir. Many studies state that production of wines by autochthonous yeasts isolated from its terroir can contribute to the regional character of the wine, especially the wine flavor [14-16]. In the present study, autochthonous S. cerevisiae and T. delbrueckii yeasts previously isolated from the spontaneous fermentation of Narince grapes were used.

$\mathrm{Cv}$. Narince is the native, and commercially important, unique white wine grape variety of the Tokat region of Turkey. Narince vineyards of the Tokat region have remarkable historical value dating back to the Hittite times-civilized 4000 years ago. Narince makes straw yellow colored wines with floral notes, yellow fruit, and citrus aromas on the nose. On the palate, it produces round, medium to full bodied wines, balanced with good acidity.

The aim of this study was to investigate the effects on the fermentation and volatile composition of Narince wines fermented by pure and mixed autochthonous T. delbrueckii-214 and S. cerevisiae-1088 cultures. To our knowledge this is the first study about the effects of autochthonous pure and mixed cultures of S. cerevisiae and T. delbrueckii yeasts on the volatile composition of Narince wines.

\section{Material and Methods}

\subsection{Yeast Strains}

The T. delbrueckii-214 (Accession number: MG017548) and S. cerevisiae-1088 (Accession number: MG017577) yeasts culture used in this study were previously isolated from spontaneous fermentations of Narince grapes. These strains were chosen due to their good technological properties such as fermentation power, fermentation vigor, higher alcohol production, and low production of volatile acidity, ethyl acetate, and acetaldehyde. The fermentation rate of T. delbrueckii-214 was $0.41 \mathrm{CO}_{2} \mathrm{~g} / \mathrm{L} \cdot \mathrm{h}$, the fermentation power was $9.40 \% v / v$ ethanol, and it produced $0.78 \mathrm{~g} / \mathrm{L}$ volatile acidity, $6.05 \mathrm{~g} / \mathrm{L}$ glycerol, $200 \mathrm{mg} / \mathrm{L}$ higher alcohol, $34 \mathrm{mg} / \mathrm{L}$ ethyl acetate, and $13 \mathrm{mg} / \mathrm{L}$ acetaldehyde. The technological properties of S. cerevisiae-1088 were previously reported by Çelik et al. [17].

\subsection{Culture Media and Chemicals}

Yeast peptone dextrose agar (YPD), YPD broth, and L-lysine agar were purchased from Sigma Aldrich (St Louis, MO, USA). Dichloromethane ( $\geq 99.9 \%$ purity), sodium sulfate anhydrous (99\%), internal standard (4-nonanol), and a mixture of n-alkane standards ranging from $\mathrm{C}_{8}-\mathrm{C}_{40}$ were purchased from Merck (Darmstadt, Germany). Standard volatile compounds used in the study were obtained from Sigma Aldrich (St Louis, MO, USA). 


\subsection{Fermentations}

Grapes from Vitis vinifera L. Narince were harvested during the 2016 vintage in the commercial vineyard of Kavaklidere, and fermentations were conducted at the experimental winery of the University of Çukurova. Narince grapes were at optimum maturity with, 20.4 brix, $5.44 \mathrm{~g} / \mathrm{L}$ titratable acids as tartaric acid, and a $\mathrm{pH}$ of 3.60. Grapes were crushed and $50 \mathrm{mg} / \mathrm{L}$ of $\mathrm{SO}_{2}$ was added. After pressing, the juice was allowed to settle $\left(10{ }^{\circ} \mathrm{C}\right.$ for $\left.12 \mathrm{~h}\right)$, separated from the lees and randomly distributed into $20 \mathrm{~L}$ glass fermentation bottles. Three different fermentations were conducted: two with the pure culture and one with the mixed culture. T. delbrueckii-2014 and S. cerevisae-1088 were inoculated at the same time (1:1) for mixed culture fermentation [11]. All fermentations were carried out in duplicate using the standard protocol for white wines: Yeast culture of T. delbrueckii-2014 and S. cerevisiae-1088 were previously grown in YPD broth at $28^{\circ} \mathrm{C}$ for $24 \mathrm{~h}$; following this, the cells were recovered by centrifugation, washed with sterile water, and added to the must at $10^{6}$ cells $\mathrm{mL} / \mathrm{L}$. All fermentations were conducted at $18{ }^{\circ} \mathrm{C}$ in a cold room. The normal development of alcoholic fermentation was checked by daily monitoring of the temperature and density values. During the first day after the initiation of fermentation, in the middle (which contained $\% 50$ sugar), and at the end of fermentation, samples of must and wine, diluted in $0.1 \%$ peptone-water (decimal dilutions), were inoculated onto plates of YPD, Lysine, and modified YPD agar (\% 10 ethanol, $v / v$ and $2 \mathrm{~g} / \mathrm{L}$ potassium metabisulfite) supplemented with chloramphenicol and sodium propionate to inhibit bacteria and filamentous fungi, respectively. Plates with YPD and modified YPD medium were incubated at $28^{\circ} \mathrm{C}$ for 2 days before counting, whereas plates with lysine agar were incubated at $25^{\circ} \mathrm{C}$ for $3-5$ days before counting $[11,18,19]$. At the end of the alcoholic fermentation, all wines were racked off gross lees and sulfur dioxide was added to yield a free $\mathrm{SO}_{2}$ of $50 \mathrm{mg} / \mathrm{L}$. After this, the wines were bottled and stored at $13-18^{\circ} \mathrm{C}$ until analysis.

\subsection{Chemical Analysis of Wines}

Density, alcohol, total acidity, $\mathrm{pH}$, volatile acidity, reducing sugar, dry matter, and total $\mathrm{SO}_{2}$, were measured according to the methods outlined by OIV [19]; glucose, fructose, and glycerol were quantified using HPLC (Shimadzu, Kyoto, Japan) according to OIV and Erten [20,21].

\subsection{Volatile Compounds Analysis}

A $100 \mathrm{~mL}$ wine sample was transferred into a $500 \mathrm{~mL}$ Erlenmeyer flask and cooled to $0{ }^{\circ} \mathrm{C}$ in an ice bath under nitrogen; 40 micrograms of 4-nonanol was added as an internal standard because of its high recovery [22]. Dichloromethane $(40 \mathrm{~mL})$ was added and the mixture was stirred at $700 \mathrm{rpm}$ for $30 \mathrm{~min}$. Then the mixture was centrifuged at $4{ }^{\circ} \mathrm{C}(9000 \times g, 15 \mathrm{~min})$. The organic phase was recovered. The organic extract dried over sodium sulfate and concentrated to a volume of $1 \mathrm{~mL}$ with a Vigreux distillation column prior to gas chromatography/mass spectrometry (GC/MS) analysis. Each sample was extracted in triplicate and the concentration of volatiles, as 4-nonanol equivalent, was obtained as the mean of three repetitions [22].

\subsection{GC-MS-FID Conditions and Identification of Volatile Compounds}

An Agilent 6890 gas chromatograph (GC) was equipped with a flame ionization detector (FID) (Wilmington, DE, USA) and an Agilent 5973-Network mass selective detector (MSD). Volatile compounds were separated on DB-Wax $(30 \mathrm{~m}$ length $\times 0.25 \mathrm{~mm}$ i.d. $\times 0.5 \mu \mathrm{m}$ thickness; J\&W Scientific Folsom, CA, USA) column and $3 \mu \mathrm{L}$ sample of extract was injected. Injector and FID detectors were set at $250{ }^{\circ} \mathrm{C}$. The flow rate of carrier gas (helium) was $1.5 \mathrm{~mL} / \mathrm{min}$. The oven temperature of the DB-Wax column was increased from $40{ }^{\circ} \mathrm{C}$ (after 3 min holding) to $90^{\circ} \mathrm{C}$ at a rate of $2{ }^{\circ} \mathrm{C} / \mathrm{min}$, then at a rate of $3{ }^{\circ} \mathrm{C} / \mathrm{min}$ to $130{ }^{\circ} \mathrm{C}$ and at a rate of $4{ }^{\circ} \mathrm{C} / \mathrm{min}$ to $240{ }^{\circ} \mathrm{C}$ with a final hold, at $240{ }^{\circ} \mathrm{C}$ for $12 \mathrm{~min}$. The same oven temperature programs were used for the mass selective detector. MS scan conditions: source temperature $120^{\circ} \mathrm{C}$, interface temperature $250{ }^{\circ} \mathrm{C}$, EI energy $70 \mathrm{eV}$, mass scan 
range 29-350 a.m.u., and a scan rate of $1.0 \mathrm{scan} / \mathrm{s}$ [22-24]. The identification of compounds was made up of the following parameters: commercial spectra database (Wiley 6, NIST 98), retention indices, an internal library created from the previous laboratory studies. Some of the identifications were confirmed by the injection of the chemical standards into the GC-MS system. Retention indices of the compounds were calculated by using an n-alkane series [22-24].

The determination of acetaldehyde and ethyl acetate was carried out by direct injection of $1 \mu \mathrm{L}$ samples into a gas chromatograph, Agilent $6890 \mathrm{~N}$ equipped with FID. Acetaldehyde and ethyl acetate separated using a Chrompack CP-WAX-57CB capillary column $(0.25 \mathrm{~mm}$ i.d. $\times 60 \mathrm{~m} \times 0.4 \mu \mathrm{m}$ film thickness) (Middelburg, The Netherlands). GC settings: injection temperature: $160{ }^{\circ} \mathrm{C}$; oven temperature: $5 \mathrm{~min}$ at $40{ }^{\circ} \mathrm{C}$, then increased by $4{ }^{\circ} \mathrm{C}$ per minute up to $102{ }^{\circ} \mathrm{C}$ and $2{ }^{\circ} \mathrm{C}$ per minute up to $125^{\circ} \mathrm{C}$ and hold for $5 \mathrm{~min}$, then $3^{\circ} \mathrm{C}$ per minute up to $160{ }^{\circ} \mathrm{C}, 6^{\circ} \mathrm{C}$ per minute up to 200, and finally hold $5 \mathrm{~min}$ at $200^{\circ} \mathrm{C}$; carrier gas: $\mathrm{He}(1.3 \mathrm{~mL} / \mathrm{min})$; split rate: $1: 50$. The quantification was performed by using equation stated reference of Cabaroğlu et al. [25] with internal standard (4-methyl-2-pentanol) method. Analysis was done in triplicate.

\subsection{Sensory Analysis}

The sensory characteristics of the final wines were evaluated according to Lawless and Heymann [26]. The sensory panel was comprised of 6 females and 4 males, 25-50 years of age, all belonging to the laboratory staff and having substantial experience of sensory analysis. The panelist used a $10 \mathrm{~cm}$ scale, from 0 (no defect) to 10 (very strong defect perceptible). Each panelist smelled and then tasted the wines in the tasting glass to detect the intensity of the 13 attributes (herb tea, citrus, tropical fruit, stone fruit, honey, herbaceous, cooked vegetable, complexity, acidity, after taste, aroma, and general impression). Sensory analysis was done in five-booth sensory panel room at $22{ }^{\circ} \mathrm{C}$ equipped with white fluorescent lighting. Wines were served $\left(50 \mathrm{~mL}\right.$ at $\left.10^{\circ} \mathrm{C}\right)$ in tulip-shaped wine glasses covered by glass petri dishes. The tasting glasses were coded with different three-digit numbers.

\subsection{Statistical Analysis}

The results were compared by the analysis of variance (ANOVA) using SPSS (for Windows version 20.0). Duncan's multiple-range tests were used to compare the significant differences of the mean values with $p<0.05$.

\section{Results and Discussion}

\subsection{Growth of the T. delbrueckii-2014 and S. cerevisiae-1088 Populations During Fermentation}

The viable yeasts population in pure and mixed culture fermentations are shown in Figures 1 and 2. In all fermentations the must was inoculated with $5 \times 10^{6}$ viable cells $/ \mathrm{mL}$ for both T. delbrueckii-214 and S. cerevisiae- 1088 and the initial must yeasts concentration following inoculation ranged from 6.1 to $6.4 \log \mathrm{cfu} / \mathrm{mL}$. The pure culture of T. delbrueckii-214 and S. cerevisiae-1088 populations reached a maximum size of 7.1 to $8.9 \log \mathrm{cfu} / \mathrm{mL}$ at the middle of fermentation. At the end of fermentation both pure T. delbrueckii-214 and S. cerevisiae-1088 populations slowly decreased, as was expected. In the mixed culture fermentation both species were added at the same time. The maximum population reached during alcoholic fermentation by T. delbrueckii-214 and S. cerevisiae-1088 was higher when inoculated alone rather than in mixed culture. At the end of the mixed culture fermentation the population of the viable T. delbruecki-214 culture had decreased. Renault et al. [27] have reported that, while $S$. cerevisiae yeast is able to quickly grow under strictly anaerobic conditions, $T$. delbrueckii is affected by a deficiency of oxygen. Competition for oxygen may explain the decrease of viable T. delbrueckii-214 population. 


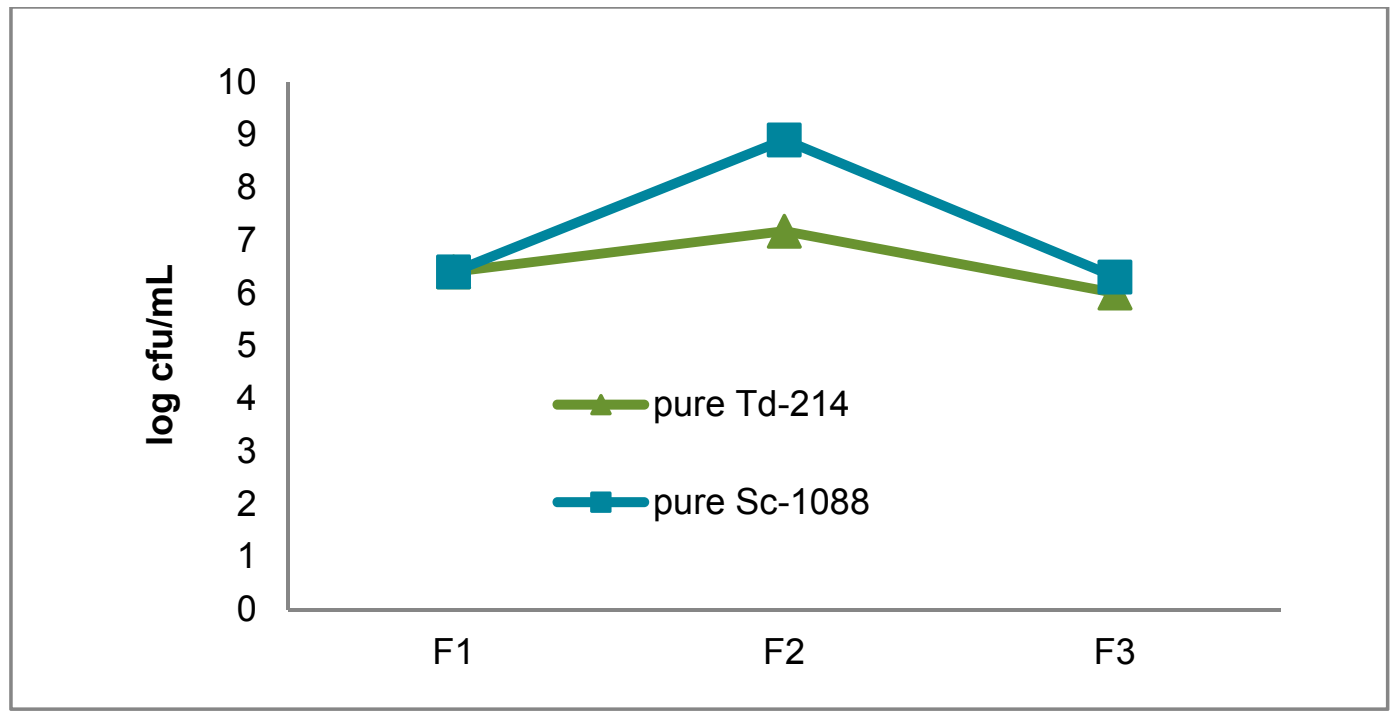

Figure 1. The growth of yeasts during pure culture fermentations. Pure Td-214: pure T. delbrueckii-214, pure Sc-1088: pure S. cerevisiae-1088. F1: beginning of fermentation. F2: middle of fermentation. F3: end of fermentation.

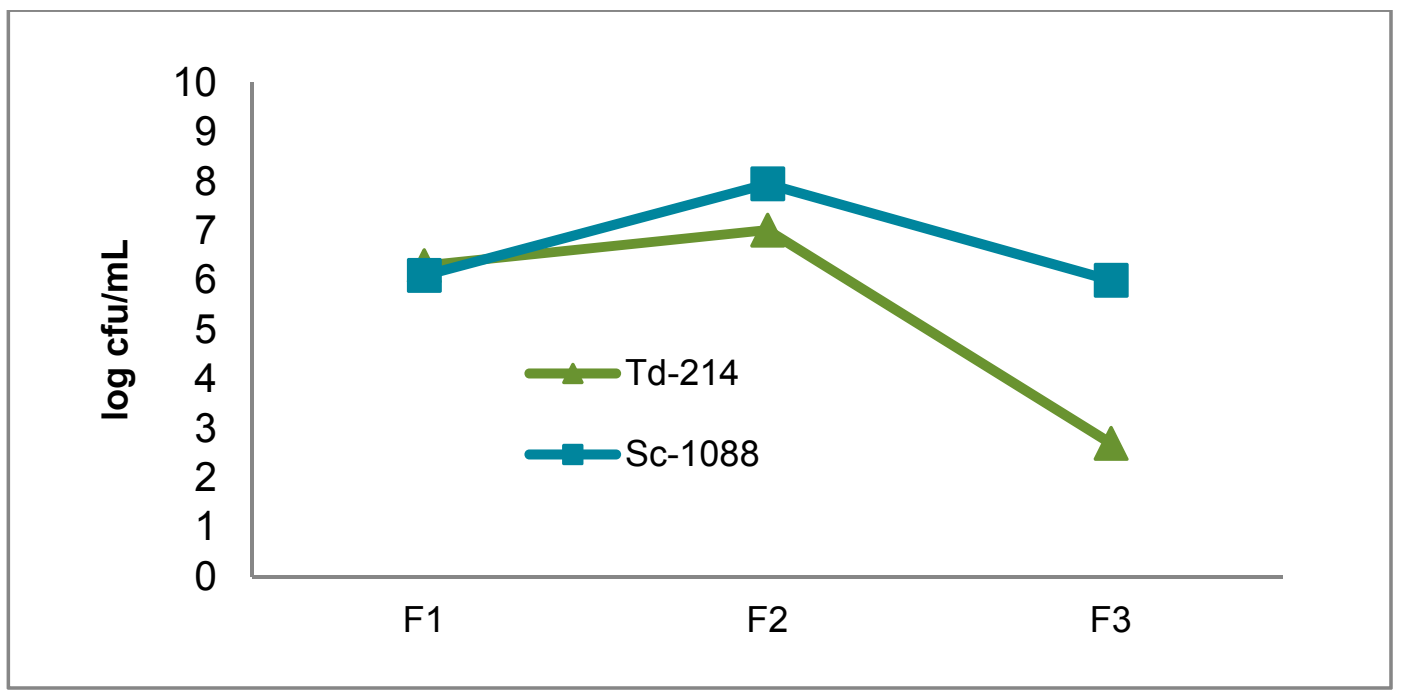

Figure 2. The growth of yeasts during mixed culture fermentation. Td-214: T. delbrueckii-214, Sc-1088: S. cerevisiae-1088. F1: beginning of fermentation. F2: middle of fermentation. F3: end of fermentation.

\subsection{Chemical Analysis of Wines}

Three fermentations were carried out in Narince musts containing $230 \mathrm{~g} / \mathrm{L}$ sugar. Alcoholic fermentation with pure S. cerevisiae-1088; mixed culture completed 13 days after inoculation, whereas pure T. delbrueckii-214 fermentation stopped after 14 days. The pure T. delbrueckii-214 culture was the only condition that did not finish the fermentation $(8 \mathrm{~g} / \mathrm{L}$ glucose and $14 \mathrm{~g} / \mathrm{L}$ fructose left in the medium) (Table 1). S. cerevisiae-1088 showed the highest fermentative ability in pure culture with the production of $11.6 v / v$, followed by mixed culture fermentation $(11.4 \% v / v)$. Fermentation performed with pure T. delbrueckii-214 produced the lowest ethanol $10.1 \% v / v$. Renault et al. [28] reported that the average value of ethanol produced by all T. delbrueckii strains was $9.88 \% v / v$. The volatile acidity of Narince wines was found to be between 0.40 and $0.58 \mathrm{~g} / \mathrm{L}$ acetic acid. The fermentation carried out with pure $S$. cerevisiae- 1088 yielded the lower volatile acidity whereas pure 
T. delbrueckii-214 yielded the highest. The level of volatile acidity in the mixed culture fermentation is between those of T. delbrueckii-214 and S. cerevisiae-1088 fermentations. T. delbrueckii is known for its ability to produce a low amount of acetic acid $[29,30]$. However in this study the fermentation with pure T. delbrueckii-214 produced the highest amount of volatile acidity. Glycerol is a wine constituent related to yeast metabolism which contributes to the sweetness, viscosity, and smoothness of wine [31]. In Narince wines glycerol production was greater in pure T. delbrueckii-214. Also the mixed T. delbrueckii-214/S. cerevisaie-1088 culture resulted in increases in glycerol, in comparison with the pure S. cerevisae-1088 culture. Renault et al. [28] reported that T. delbrueckii is a low glycerol producer, but this is strain dependent. The remaining sugar content of wines was found to be less than $3 \mathrm{~g} / \mathrm{L}$ in wines produced with pure S. cerevisiae-1088 and mixed culture and is compatible with the concentration for dry wines. But as mentioned above, T. delbrueckii-214 did not ferment grape juice to dryness.

Table 1. General compositions of Narince wines.

\begin{tabular}{|c|c|c|c|c|}
\hline General Composition & Td-214 & Sc-1088 & MC & $\mathbf{F}$ \\
\hline Alcohol $(\% v / v)$ & $10.12 \pm 0.0^{\mathrm{a}}$ & $11.6 \pm 0.2^{b}$ & $11.48 \pm 0.0^{\mathrm{b}}$ & * \\
\hline Total acidity ** & $7.04 \pm 0.0^{\mathrm{b}}$ & $6.05 \pm 0.0^{\mathrm{a}}$ & $6.56 \pm 0.0^{b}$ & * \\
\hline $\mathrm{pH}$ & $3.68 \pm 0.0^{\mathrm{a}, \mathrm{b}}$ & $3.66 \pm 0.0^{\mathrm{a}}$ & $3.71 \pm 0.0^{b}$ & * \\
\hline Volatile acidity $(\mathrm{g} / \mathrm{L})^{* * *}$ & $0.58 \pm 0.0^{\mathrm{c}}$ & $0.40 \pm 0.0^{\mathrm{a}}$ & $0.43 \pm 0.0^{b}$ & * \\
\hline Total $\mathrm{SO}_{2}$ & $56 \pm 1$ & $56 \pm 0.5$ & $57 \pm 0.2$ & ns \\
\hline Dry matter $(\mathrm{g} / \mathrm{L})$ & $21.6 \pm 0.0$ & $21.9 \pm 0.0$ & $21.7 \pm 0.0$ & ns \\
\hline Glycerol & $7.37 \pm 0.3^{b}$ & $5.93 \pm 0.0^{\mathrm{a}}$ & $6.06 \pm 0.1^{\mathrm{a}}$ & $*$ \\
\hline \multicolumn{5}{|l|}{ Sugars (g/L) } \\
\hline Glucose & $8.06 \pm 0.1^{\mathrm{c}}$ & $0.95 \pm 0.0^{\mathrm{a}}$ & $1.26 \pm 0.0^{b}$ & * \\
\hline Fructose & $14.25 \pm 0.0^{\mathrm{c}}$ & $0.87 \pm 0.0^{\mathrm{a}}$ & $1.52 \pm 0.0^{b}$ & * \\
\hline Total & 22.31 & 1.82 & 2.78 & \\
\hline
\end{tabular}

Td-214: T. delbrueckii-214, Sc-1088: S. cerevisiae-1088, MC: Mixed culture of T. delbrueckii-2014 and S. cerevisiae-1088. F: significance at which means differ as shown using analysis of variance ${ }^{*} p<0.05$ level. ${ }^{* *}$ : As tartaric acid, ${ }^{* * *}$ : As acetic acid.

\subsection{Volatile Composition of the Narince Wines Produced in the Pure and Mixed Culture}

Table 2 shows volatile compounds of Narince wines fermented with pure and mixed culture of T. delbrueckii-214 and S. cerevisiae-1088. A total of 47 volatile compounds were quantified in Narince wines including 15 higher alcohols, 15 esters, 10 volatile acids, two carbonyl compounds, three lactones, and two volatile phenols. Significant differences in the volatile composition of the wines were observed in those obtained from mixed culture fermentations, as well as those obtained from pure culture fermentations. The pure T. delbrueckii-214 has the highest $(396.7 \mathrm{mg} / \mathrm{L})$ concentration of total volatile compounds due to production of a high level of acetaldehyde, whereas the pure S. cerevisiae fermentation has the lowest $(253.6 \mathrm{mg} / \mathrm{L})$ concentration. The concentration of total volatile compounds in the mixed culture fermentation $(291.2 \mathrm{mg} / \mathrm{L})$ was found between those of the pure T. delbrueckii-214 and S. cerevisiae- 1088 fermentation. 
Table 2. Volatile composition of the Narince wines produced in the pure and mixed culture.

\begin{tabular}{|c|c|c|c|c|c|c|}
\hline \multicolumn{7}{|c|}{ AROMAC OMPOUNDS $(\mu \mathrm{g} / \mathrm{L})$} \\
\hline Higher alcohols & RI & Td-214 & Sc-1088 & $\mathrm{Td}+\mathrm{Sc}$ & $\mathbf{F}$ & ID \\
\hline 1-Propanol & 1037 & $1702.4 \pm 7^{\mathrm{b}}$ & $1224.5 \pm 64^{\mathrm{a}}$ & $1283.0 \pm 5^{a}$ & * & RI, MS, Std \\
\hline Isobutyl alcohol & 1085 & $10,621.5 \pm 62^{b}$ & $9123.2 \pm 153^{\mathrm{a}}$ & $10,649.2 \pm 1012^{b}$ & * & RI, MS, Std \\
\hline 1-Butanol & 1165 & $617.9 \pm 1^{c}$ & $309.6 \pm 29^{a}$ & $400.5 \pm 59^{b}$ & * & RI, MS, Std \\
\hline Isoamyl alcohol & 1210 & $120,544.6 \pm 757^{\mathrm{a}}$ & $144,208.5 \pm 1146^{b}$ & $167,995.9 \pm 459^{c}$ & * & RI, MS, Std \\
\hline 2-Hexanol & 1226 & $200.0 \pm 9^{a}$ & $295.0 \pm 20^{c}$ & $246.4 \pm 13^{b}$ & * & RI, MS, Std \\
\hline 3-Pentanol & 1295 & $104.0 \pm 2^{c}$ & $67.2 \pm 0^{\mathrm{a}}$ & $73.6 \pm 1^{\mathrm{b}}$ & * & RI, MS, Std \\
\hline 1-Hexanol & 1370 & $1329.5 \pm 4^{b}$ & $1249.5 \pm 25^{\mathrm{a}}$ & $1228.9 \pm 18^{a}$ & * & RI, MS, Std \\
\hline (E)-3-Hexen-1-ol & 1386 & $3.2 \pm 0^{\mathrm{a}}$ & $136.8 \pm 4^{c}$ & $116.4 \pm 2^{b}$ & * & RI, MS, Std \\
\hline 3-Ethoxy-1-propanol & 1390 & $741.6 \pm 1^{c}$ & $43.9 \pm 1^{a}$ & $162.9 \pm 5^{b}$ & $*$ & RI, MS, Std \\
\hline (Z)-3-Hexen-1-nol & 1401 & $104.4 \pm 4$ & $103.2 \pm 5$ & $93.4 \pm 7$ & ns & RI, MS, Std \\
\hline 2,3-Butanediol & 1495 & $771.6 \pm 9^{a}$ & $1371.7 \pm 19^{c}$ & $1029.1 \pm 42^{b}$ & $*$ & RI, MS, Std \\
\hline 1,3-Butanediol & 1566 & $296.5 \pm 2^{c}$ & $239.7 \pm 1^{b}$ & $215.9 \pm 13^{\mathrm{a}}$ & * & RI, MS \\
\hline Methionole & 1737 & $1746.5 \pm 8^{c}$ & $590.9 \pm 5^{a}$ & $722.7 \pm 11^{b}$ & * & RI, MS, Std \\
\hline Benzyl alcohol & 1804 & $36.2 \pm 2^{\mathrm{a}}$ & $59.9 \pm 4^{c}$ & $46.9 \pm 0^{\mathrm{b}}$ & * & RI, MS, Std \\
\hline 2-Phenyl ethanol & 1916 & $48,153.0 \pm 337^{c}$ & $32,738.2 \pm 584^{\mathrm{a}}$ & $35,718.7 \pm 765^{b}$ & * & RI, MS, Std \\
\hline Sum & & $186,971.5$ & $191,755.8$ & $219,983.5$ & & \\
\hline \multicolumn{7}{|l|}{ Esters } \\
\hline Ethyl acetate ** & 895 & $38,712.4 \pm 1266^{b}$ & $29,309.0 \pm 499^{\mathrm{a}}$ & $36,891.9 \pm 1894^{b}$ & * & MS, RI \\
\hline Isoamyl acetate & 1119 & $646.6 \pm 0^{\mathrm{a}}$ & $1336.7 \pm 37^{b}$ & $1565.2 \pm 62^{c}$ & * & RI, MS, Std \\
\hline Ethyl hexanoate & 1241 & $826.5 \pm 8^{a}$ & $1403.6 \pm 6^{b}$ & $1438.5 \pm 41^{\mathrm{b}}$ & * & RI, MS, Std \\
\hline Hexyl acetate & 1250 & $117.9 \pm 0^{a}$ & $202.6 \pm 7^{b}$ & $190.7 \pm 12^{b}$ & * & RI, MS, Std \\
\hline Ethyl lactate & 1353 & $978.2 \pm 4^{c}$ & $609.0 \pm 8^{\mathrm{a}}$ & $775.6 \pm 18^{b}$ & * & RI, MS, Std \\
\hline Ethyl octanoate & 1430 & $173.8 \pm 5^{\mathrm{a}}$ & $1226.1 \pm 8^{c}$ & $1052.6 \pm 10^{b}$ & * & RI, MS, Std \\
\hline Ethyl-3-hydroxybutyrate & 1524 & nd & $109.2 \pm 1^{\mathrm{a}}$ & $116.4 \pm 2^{b}$ & * & RI, MS, Std \\
\hline Ethyl decanoate & 1635 & $28.3 \pm 2^{\mathrm{a}}$ & $300.3 \pm 1^{c}$ & $232.2 \pm 7^{b}$ & * & RI, MS, Std \\
\hline 1,3-Propanediol diacetate & 1650 & $258.1 \pm 0^{c}$ & $194.5 \pm 7^{\mathrm{a}}$ & $223.8 \pm 6^{b}$ & * & RI, MS \\
\hline Diethyl succinate & 1690 & $152.2 \pm 4^{\mathrm{a}}$ & $248.9 \pm 5^{c}$ & $215.9 \pm 4^{b}$ & * & RI, MS, Std \\
\hline Ethyl-4-hydroxybutyrate & 1819 & $656.6 \pm 0^{a}$ & $4202.7 \pm 22^{c}$ & $3945.0 \pm 120^{b}$ & * & RI, MS \\
\hline Ethyl dodecanoate & 1851 & $26.6 \pm 1^{a}$ & $83.2 \pm 3^{c}$ & $73.6 \pm 0^{\mathrm{b}}$ & $*$ & RI, MS, Std \\
\hline Diethyl-dL-malate & 2041 & $108.3 \pm 10$ & $115.2 \pm 2$ & $116.8 \pm 1$ & ns & RI, MS, Std \\
\hline Ethyl hexadecanoate & 2259 & $132.9 \pm 2^{a}$ & $234.1 \pm 12^{\mathrm{b}}$ & $124.4 \pm 6^{\mathrm{a}}$ & $*$ & RI, MS, Std \\
\hline Ethyl hydrogen succinate & 2331 & $2778.7 \pm 63^{c}$ & $1884.5 \pm 106^{\mathrm{a}}$ & $2524.4 \pm 169^{b}$ & * & RI, MS \\
\hline Sum & & $45,597.1$ & $41,459.6$ & $49,263.2$ & & \\
\hline \multicolumn{7}{|l|}{ Volatile acids } \\
\hline Propionic acid & 1538 & $53.5 \pm 0^{a}$ & $71.8 \pm 0^{\mathrm{b}}$ & $71.7 \pm 2^{b}$ & * & RI, MS, Std \\
\hline Isobutanoic acid & 1584 & $1052.1 \pm 6^{c}$ & $373.1 \pm 5^{\mathrm{a}}$ & $526.5 \pm 23^{b}$ & * & RI, MS, Std \\
\hline Butanoic acid & 1628 & $211.6 \pm 4^{\mathrm{a}}$ & $295.5 \pm 4^{b}$ & $338.4 \pm 15^{c}$ & * & RI, MS, Std \\
\hline Isovaleric acid & 1608 & $365.1 \pm 5^{\mathrm{a}}$ & $633.0 \pm 11^{b}$ & $625.8 \pm 14^{b}$ & * & RI, MS, Std \\
\hline Hexanoic acid & 1840 & $787.6 \pm 3^{a}$ & $2355.7 \pm 70^{b}$ & $2381.1 \pm 62^{b}$ & $*$ & RI, MS, Std \\
\hline (E)-2-Hexenoic acid & 1962 & $150.0 \pm 13$ & $134.9 \pm 6$ & $128.3 \pm 6$ & ns & RI, MS, Std \\
\hline Octanoic acid & 2060 & $624.6 \pm 3^{a}$ & $3383.2 \pm 112^{c}$ & $3152.5 \pm 98^{b}$ & $*$ & RI, MS, Std \\
\hline Nonanoic acid & 2158 & $94.1 \pm 1$ & $101.5 \pm 26$ & $70.6 \pm 6$ & ns & RI, MS, Std \\
\hline Decanoic acid & 2183 & $40.6 \pm 1^{\mathrm{a}}$ & $573.1 \pm 36^{b}$ & $623.3 \pm 16^{c}$ & * & RI, MS \\
\hline 9-Decenoic acid & 2237 & $611.4 \pm 11^{\mathrm{b}}$ & $293.9 \pm 17^{\mathrm{a}}$ & $269.5 \pm 9^{\mathrm{a}}$ & $*$ & RI, MS \\
\hline Sum & & 3990.6 & 8215.6 & 8187.9 & & \\
\hline Carbonyl compounds & RI & Td-214 & Sc-1088 & MC & F & ID \\
\hline Acetoin & 1291 & $1448.5 \pm 3^{b}$ & $307.9 \pm 4^{\mathrm{a}}$ & $299.1 \pm 21^{\mathrm{a}}$ & * & RI, MS, Std \\
\hline Acetaldehyde ${ }^{* *}$ & 500 & $157,040.7 \pm 3248^{b}$ & $9631.6 \pm 499^{a}$ & $11,237.0 \pm 726^{a}$ & $*$ & MS, RI \\
\hline Sum & & $158,489.2$ & 9939.5 & $11,536.1$ & & \\
\hline \multicolumn{7}{|l|}{ Lactones } \\
\hline$\gamma$-Butyrolactone & 1635 & $1185.2 \pm 4^{\mathrm{a}}$ & $1726.8 \pm 12^{b}$ & $1770.8 \pm 46^{b}$ & * & RI, MS, Std \\
\hline Pantolactone & 2414 & $146.7 \pm 3^{b}$ & $83.9 \pm 22^{\mathrm{a}}$ & $59.6 \pm 1^{\mathrm{a}}$ & * & RI, MS, Std \\
\hline 4-Ethoxycarbonyl- $\gamma$-butyrol & 2673 & $85.9 \pm 1^{\mathrm{a}}$ & $262.4 \pm 7^{c}$ & $229.9 \pm 0^{b}$ & * & RI, MS \\
\hline Sum & & 1417.9 & 2073 & 2060.4 & & \\
\hline \multicolumn{7}{|l|}{ Volatile phenols } \\
\hline 4-Vinylguaicol & 2091 & $215.3 \pm 3^{c}$ & $198.6 \pm 0^{b}$ & $172.4 \pm 6^{\mathrm{a}}$ & * & RI, MS, Std \\
\hline Acetovanillone & 2995 & $50.3 \pm 0^{\mathrm{b}}$ & $54.6 \pm 0^{c}$ & $32.2 \pm 0^{\mathrm{a}}$ & $*$ & RI, MS, Std \\
\hline Sum & & 265.6 & 253.2 & 204.6 & & \\
\hline Total Sum & & $396,731.9$ & $253,696.7$ & $291,235.7$ & & \\
\hline
\end{tabular}

Td-214: T. delbrueckii-214, Sc-1088: S. cerevisiae-1088, MC: Mixed culture of T. delbrueckii-2014 and S. cerevisiae-1088. RI: retention index calculated on DBWax capillary column, MS: mass spectrometry, Std: chemical standard, \pm : Standard deviation, nd: not detected, F: significance at which means differ as shown using analysis of variance, *: important at $p<0.05$ level, a-c: different superscripts in the same row indicate statistical differences at the $p<0.05$ level, ns: not significant. **: Determined by direct injection into GC. 
Higher alcohols are produced from the Erlich pathway in the presence of amino acids and from sugar via biosynthesis by yeasts during alcoholic fermentation [32]. This group was the largest group of volatile compounds determined in Narince wines. The wine fermented with mixed culture had the highest total higher alcohol concentration $(219.9 \mathrm{mg} / \mathrm{L})$, followed by the wine fermented with pure S. cerevisiae-1088 (191.7 mg/L), and the wine fermented with pure T. delbrueckii-214 (186.9 mg/L). At concentrations below $300 \mathrm{mg} / \mathrm{L}$, they contribute to the desirable complexity of wine. When their concentration exceeds $400 \mathrm{mg} / \mathrm{L}$, higher alcohols are regarded as a negative quality factor [33,34]. In all Narince wines, the concentrations of total higher alcohols found were below the $300 \mathrm{mg} / \mathrm{L}$ threshold. Isoamyl alcohol and 2-phenyl ethanol were the most abundant higher alcohols in all Narince wines. The wine fermented with mixed culture had highest concentration of isoamyl alcohol. However, the wine fermented with pure culture of T. delbrueckii-214 presented a significantly higher concentration of 2-phenyl ethanol. The odor threshold values of isoamyl alcohol and 2-phenylethyl alcohol are $30 \mathrm{mg} / \mathrm{L}$ and $10 \mathrm{mg} / \mathrm{L}$, respectively. Isoamyl alcohol has a harsh aroma, whereas 2-phenylethyl alcohol has a floral and rose-like aroma and contributes positively to wine aroma [33]. Concentration of these compounds exceeded their threshold values in all Narince wines. The development of T. delbrueckii-214 also significantly increased the production of certain higher alcohols, such as 1-propanol, n-butanol, 3-ethoxy-1-propanol, and methionol in wines. Methionol has cooked potato, cauliflower notes and it exceed its threshold value of $1 \mathrm{mg} / \mathrm{L}$ [10] in wine fermented with pure T. delbrueckii-214. Azzolini et al. reported [35] that T. delbrueckii increased the amount of methionol in Chardonnay wines.

Esters are an important group of volatile compounds and they are mainly produced by yeast metabolism during alcoholic fermentation [33]. Commercial wine strains produce different amounts of esters, such as ethyl acetate, isoamyl acetate, hexyl acetate, ethyl hexanoate, and ethyl octanoate, which have a potential influence on the aroma profile of wine. Also, there are several non-Saccharomyces wine yeasts that can positively effect of the ester profiles of wines which can be used as a mixed culture with S. cerevisiae $[4,33]$. The pure S. cerevisiae- 1088 fermentation produced less total esters $(41.4 \mathrm{mg} / \mathrm{L})$ than the others. In the mixed culture fermentation, overall ester production was higher $(49.2 \mathrm{mg} / \mathrm{L})$ than in both pure cultures. The concentration of total esters in the pure T. delbrueckii-214 fermentation $(45.5 \mathrm{mg} / \mathrm{L})$ was found between those of the pure S. cerevisiae-1088 and mixed culture fermentations. It has been reported that ester production by T. delbrueckii is strain-dependent and results are different when T. delbrueckii is associated with S. cerevisiae in mixed culture [1]. Ethyl acetate was found as the highest amount of ester compound in all Narince wines. This compound may contribute with a pleasant fruity fragrance to the general wine aroma at low concentration, whereas it contributes significantly do defect aroma at a concentration between 150 and $200 \mathrm{mg} / \mathrm{L}$ [34]. In the present study, the concentration of ethyl acetate was found between $29.2 \mathrm{mg} / \mathrm{L}$ and $38.7 \mathrm{mg} / \mathrm{L}$ and the pure T. delbrueckii-214 produced the highest amount of ethyl acetate in Narince wine. The aroma threshold value of ethyl acetate is $7.5 \mathrm{mg} / \mathrm{L}$ [33], and it exceeded its odor threshold value in all Narince wines. Other esters, isoamyl acetate, ethyl hexanoate, hexyl acetate, ethyl octanoate, ethyl decanoate, diethyl succinate, and ethyl-4-hydroxybutyrate were found at much lower concentrations in the pure T. delbrueckii-214 fermentation compared to the pure S. cerevisiae-1088 and mixed culture fermentations. On the other hand, ethyl lactate and ethyl hydrogen succinate were found at higher concentration in the pure T. delbrueckii-214 fermentation. Nevertheless, the concentrations of isoamyl acetate $(0.03 \mathrm{mg} / \mathrm{L})$, ethyl hexanoate $(0.05 \mathrm{mg} / \mathrm{L})$, and ethyl octanoate $(0.02 \mathrm{mg} / \mathrm{L})$ were detected at levels much higher than their threshold values [17] in all Narince wines. These compounds give wine pleasant aromas such as banana, pear, green apple, sweet soap, respectively [33].

The production of volatile acids in Narince wines by pure inoculation with S. cerevisiae- 1088 was found to be significantly higher $(8.2 \mathrm{mg} / \mathrm{L})$. T. delbrueckii-214 fermentation produced much lover $(3.9 \mathrm{mg} / \mathrm{L})$ volatile acids than the others. But $\mathrm{T}$. delbrueckii-214 significantly affected the accumulation of isobutyric acid and 9-decanoic acid. As indicated in Table 2, isobutyric acid was the most abundant volatile acid in wine fermented with pure T. delbrueckii-214, whereas hexanoic and octanoic acids were the most abundant volatile acids in wines fermented with pure S. cerevisiae- 1088 and mixed culture. 
Two carbonyl compounds, acetoin and acetaldehyde were detected in all Narince wines. Acetaldehyde is a major carbonyl compound found in wine with concentration $10 \mathrm{mg} / \mathrm{L}-75 \mathrm{mg} / \mathrm{L}$ and the sensory threshold value $100 \mathrm{mg} / \mathrm{L}[17,32]$. At low levels it gives pleasant fruity aroma, but at high concentrations it has a pungent irritating odor [36]. In Narince wines acetaldehyde concentration was found between $9.6 \mathrm{mg} / \mathrm{L}$ and $157.0 \mathrm{mg} / \mathrm{L}$. Acetaldehyde concentration was found to be higher in wine fermented with pure T. delbrueckii-214 culture and it exceeded its threshold value. Acetaldehyde production by yeasts effected by various factors, such as temperature, oxygen, and $\mathrm{SO}_{2}$ [36] T. delbrueckii species is considered to have a high industrial potential due to its low production of undesirable byproducts such as acetaldehyde and acetoin [11,12]. However in this study, the concentration of acetoin and acetaldehyde were found higher in wine inoculated with pure T. delbrueckii-214. The production of carbonyl compounds by mixed and pure S.cerevisiae-1088 cultures was significantly lower than in the pure T. delbrueckii-2014.

Table 2 shows the lactones of the Narince wines. Total lactones were found higher in the wine inoculated with pure S. cerevisiae-1088. This increase was due to $\gamma$-butyrolactone. However the concentration of $\gamma$-butyrolactone found was much lower than its threshold value of $35 \mathrm{mg} / \mathrm{L}$ [33] in all Narince wines.

Two volatile phenols, 4-vinylguaciol and acetovanillone were detected in Narince wines. Both T. delbrueckii-214 and S. cerevisiae-1088 produced small amounts of volatile phenols. However, 4-vinylguaicol and acetovanillone were found higher in wine inoculated with pure T. delbrueckii-214 compare to wine inoculated with pure S. cerevisae-1088 and mixed culture. Odor threshold values of 4-vinylguaciol and acetovanillone are $10 \mathrm{mg} / \mathrm{L}$ [33] and $1 \mathrm{mg} / \mathrm{L}$ [37], respectively. But concentrations of these compounds found below their threshold values.

\subsection{Sensory Analysis of the Narince Wines Produced in the Pure and Mixed Culture}

Figure 3 shows the sensory analysis results of Narince wines. Wine fermented with mixed culture of T. delbrueckii-214 and S. cerevisiae-1088 obtained higher scores in herbal tea, citrus, tropical fruit, honey attributes, and followed by the wine fermented with pure S. cerevisiae- 1088 culture. The wine fermented with pure T. delbrueckii-214 scored highest in stone fruit and cooked vegetable attributes. The unpleasant cooked vegetable attribute was probably due to higher level production of methionol. The aroma intensity and complexity attributes were greater in mixed culture fermentation compared to pure culture fermentations. This Narince wine, which is fermented with mixed culture, is the most preferred wine compared to others. Gonzales-Rayo et al. [11] have reported that Macabeo wine inoculated with a mixed culture of T. delbrueckii and S. cerevisiae was the most preferred wine among the others.

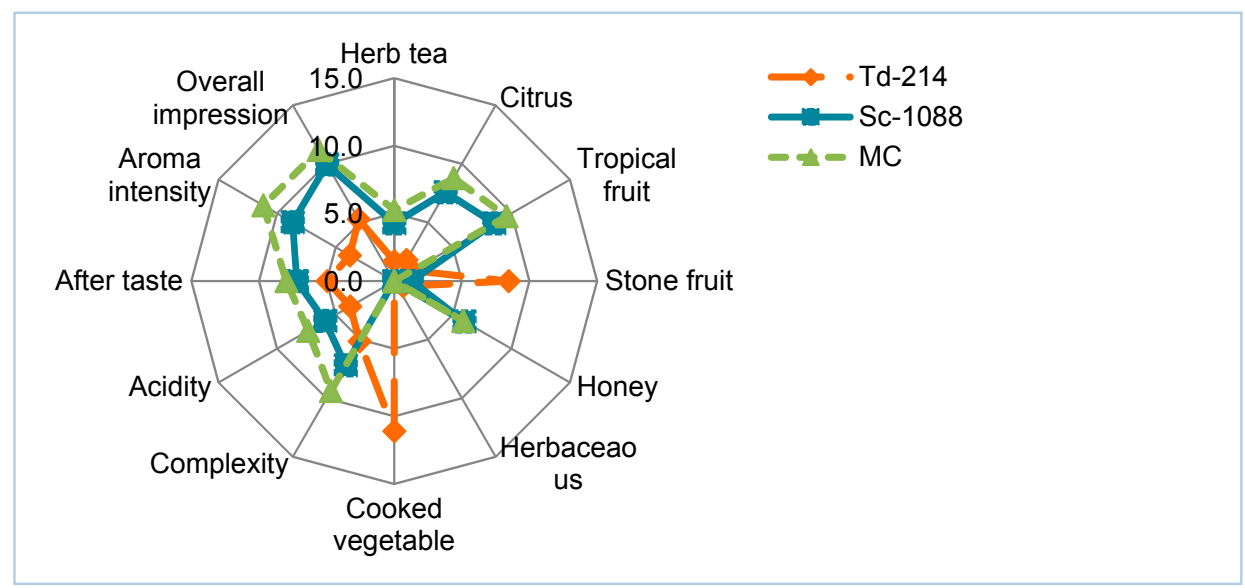

Figure 3. Sensory analysis of Narince wines produced in the pure and mixed culture. Td-214: T. delbrueckii-214, Sc-1088: S. cerevisiae-1088, MC: Mixed culture of T. delbrueckii-214 and S.cerevisiae-1088. 


\section{Conclusions}

The current study examined the effects of pure and mixed autochthonous T. delbrueckii-214 and S.cerevisiae-1088 on fermentation and volatile composition of Narince wines. Fermentation with mixed culture of T. delbrueckii-214/S. cerevisiae-1088 demonstrated significant differences distinguishing the chemical and sensory properties, compared to pure culture fermentations with T. delbrueckii-214 and S. cerevisiae-1088. Autochthonous T. delbrueckii-214 yeast slowed down the fermentation and produced a lower level of ethanol and a higher level of glycerol and volatile acid. T. delbrueckii also has some effects on wine quality and aroma composition during fermentation. These effects are a reduction of the main ester concentrations, an increase in concentration of carbonyl compounds, some higher alcohols, and minor ethyl esters. The results indicated that the presence of T. delbrueckii-214 in the mixed culture fermentation significantly increased the levels of isoamyl alcohol, 2-phenyl ethanol, ethyl acetate, isoamyl acetate, ethyl lactate, ethyl hydrogen succinate, and isobutanoic acid that may be responsible for, and improved the intensity of, the aroma and complexity of Narince wine. However, industrial large-scale fermentations are needed to confirm these results.

Author Contributions: Experimental desing, T.C. and Z.D.Ç.; Laboratory tests and analysis, E.A. and Z.D.Ç.; Supervision, T.C.; Writing orginal draft, E.A. and Z.D.Ç.; Writting-review and editing, Z.D.Ç. and T.C.

Funding: This research was financially supported by Scientific Project Unit of Çukurova University (Research Project No: FYL-2016-6851).

Acknowledgments: The grape samples of this research were provided by Kavaklıdere Wine Company.

Conflicts of Interest: The authors declare no conflict of interest.

\section{References}

1. Renault, P.; Coulon, J.; de Revel, G.; Barbe, J.C.; Bely, M. Increase of fruity aroma during mixed T. delbrueckii/ S. cerevisiae wine fermentation is linked to specific esters enhancement. Int. J. Food Microbiol. 2015, 207, 40-48. [CrossRef] [PubMed]

2. Andorrá, I.; Berradre, M.; Rozès, N.; Mas, A.; Guillamón, J.M.; Esteve-Zarzosa, B. Effect of pure and mixed cultures of the main wine yeast species on grape must fermentations. Eur. Food Res. Technol. 2010, 231, 215-224. [CrossRef]

3. Petruzzi, L.; Capozzi, V.; Berbegal, C.; Corbo, R.M.; Bevilacqua, A.; Spano, G.; Sinigaglia, M. Microbial resources and enological significance: Opportunities and benefits. Front. Mircobiol. 2017, 8, 1-13. [CrossRef] [PubMed]

4. Capozzi, V.; Garofalo, C.; Chiriatti, M.A.; Grieco, F.; Spano, G. Microbial terroir and food innovation: The case of yeast biodiversity in wine. Microbiol. Res. 2015, 181, 75-83. [CrossRef] [PubMed]

5. Jolly, N.P.; Varela, C.; Pretorius, I.S. Not your ordinary yeast: Non-Saccharomyces yeasts in wine production uncovered. FEMS Yeast Res. 2014, 14, 215-237. [CrossRef] [PubMed]

6. Bauer, F.F.; Pretorius, I.S. Yeast stress response and fermentation efficiency: How to survive the making of wine-A Review. S. Afr. J. Enol. Vitic. 2000, 21, 27-49.

7. Jemec, K.P.; Cadez, N.; Zagorc, T.; Bubic, V.; Zupec, A.; Raspor, P. Yeast population dynamics in five spontaneous fermentations of Malvasia must. Food Microbiol. 2001, 18, 247-259. [CrossRef]

8. Loira, I.; Vejarano, R.; Bañuelos, M.A.; Morata, A.; Tesfaye, W.; Uthurry, C.; Villa, A.; Cintora, I.; Suárez-Lepe, J.A. Influence of sequential fermentation with Torulaspora delbrueckii and Saccharomyces cerevisiae on wine quality. Food Sci. Technol. 2014, 59, 915-922. [CrossRef]

9. Comitini, F.; Gobbi, M.; Domizio, P.; Romani, C.; Lencioni, L.; Mannazzu, I.; Ciani, M. Selected non-Saccharomyces wine yeasts in controlled multistarter fermentations with Saccharomyces cerevisiae. Food Microbiol. 2011, 28, 873-882. [CrossRef] [PubMed]

10. Clemente-Jiménez, J.M.; Mingorance-Cazorla, L.; Martínez-Rodríguez, S.; Heras-Vázquez, F.J.L; Rodriguez-Vico, F. Molecular characterization and oenological properties of wine yeasts isolated during spontaneous fermentation of six varieties of grape must. Food Microbiol. 2004, 21, 149-155. [CrossRef]

11. Ciani, M.; Beco, L.; Comitini, F. Fermentation behaviour and metabolic interaction of multistarter wine yeast fermentations. Int. J. Food Microbiol. 2006, 108, 239-245. [CrossRef] [PubMed] 
12. Barbegal, C.; Spano, G.; Tristezza, M.; Grieco, F.; Capozzi, V. Microbial resources and innovation in the wine production sector. S. Afr. J. Enol. Vitic. 2017, 38, 156-166. [CrossRef]

13. Velázquez, R.; Zamora, E.; Alvarez, M.L.; Hernández, L.M.; Ramírez, M. Effects of new Torulaspora delbrueckii killer yeasts on the must fermentation kinetics and aroma compounds of the white table wine. Front. Microbiol. 2015, 6, 10-11. [CrossRef] [PubMed]

14. Capece, A.; Siesto, G.; Poeta, C.; Pietrafesa, R.; Romano, P. Indigenous yeast population from Georgia aged wines produced by traditional "Kakhetian" method. Food Microbiol. 2013, 36, 447-455. [CrossRef] [PubMed]

15. Agarbati, A.; Canonico, L.; Ciani, M.; Comitini, F. Fitness of selected indigenous Saccharomyces cerevisiae strains for white Piceno DOC wines production. Fermentation 2018, 4, 37. [CrossRef]

16. Capece, A.; Romaniello, R.; Pietrafesa, R.; Romano, P. Indigenous Saccharomyces cerevisiae yeasts as a source of biodiversity for the selection of starters for specific fermentations. BIO Web Conf. 2014, 3, 1-6. [CrossRef]

17. Çelik, Z.D.; Erten, H.; Darıcı, M.; Cabaroğlu, T. Molecular characterization and technological properties of wine yeasts isolated during spontaneous fermentation of Vitis vinifera L. cv. 'Narince' grape must grow in ancient wine making area Tokat, Anatolia. BIO Web Conf. 2017, 9, 1-7. [CrossRef]

18. Capece, A.; Pietrafesa, R.; Romano, P. Experimental approach for target slection of wild wine yeasts from spontaneous fermentation of 'Inzolia' grapes. World J. Microbiol. Biotechnol. 2011, 27, 2775-2783. [CrossRef]

19. Zohre, D.E.; Erten, H. The influence of Kloeckera apiculata and Candida pulcherrima yeasts on wine fermentation. Process Biochem. 2002, 38, 319-324. [CrossRef]

20. OIV. Compendium of International Methods of Analysis of Wine and Musts; International Organisation of Vine and Wine: Paris, France, 2015; Volume 1.

21. Erten, H. Metabolism of fructose as an electron acceptor by Leuconostoc mesenteroides. Process Biochem. 1998, 33, 735-739. [CrossRef]

22. Selli, S.; Cabaroğlu, T.; Canbaş, A.; Erten, H.; Nurgel, C.; Lepoutre, J.P.; Günata, Z. Volatile composition of red wine from cv. Kalecik karası grown in central Anatolia. Food Chem. 2004, 85, 207-213. [CrossRef]

23. Schneider, R.; Baumes, R.; Bayanove, C.; Razungles, A. Volatile compounds involved in the aroma of sweet of fortified wines (Vins Doux Naturels) from Grenache Noir. J. Agric. Food Chem. 1998, 46, 3230-3237. [CrossRef]

24. Schneider, R.; Razungles, A.; Augier, C.; Baumes, R. Monoterpenic and norisoprenoidic glycoconjugates of Vitis vinifera L. cv. Melon B. As precursors of odorants in Muscadet wines. J. Chrom. A 2001, 936, 145-157. [CrossRef]

25. Cabaroğlu, T.; Yilmaztekin, M. Methanol and major volatile compounds of Turkish raki and effect distillate source. J. Inst. Brew. 2011, 117, 98-105. [CrossRef]

26. Lawless, H.T.; Heymann, H. Sensory Evaluation of Food, 2nd ed.; Springer: New York, NY, USA, 2010; pp. 231-238, ISBN 978-1-4419-6487-8.

27. Renault, P.; Coulon, J.; Moine, V.; Thibon, C.; Bely, M. Enhanced 3-sulfanylhexan-1-ol production in sequential mixed fermentation with Torulaspora delbrueckii/Saccharomyces cerevisiae reveals a situation of synergistic interaction between two industrial strains. Front. Microbiol. 2016, 7, 293. [CrossRef] [PubMed]

28. Renault, P.; Miot-Sertier, C.; Marullo, P.; Hernández-Orte, P.; Lagarrigue, L.; Lonvaud-Funel, A.; Bely, M. Genetic characterization and phenotypic variability in Torulaspora delbrueckii species: Potential applications in the wine industry. Int. J. Food Microbiol. 2009, 134, 201-210. [CrossRef] [PubMed]

29. González-Royo, E.; Pascul, O.; Kontoudakis, N.; Esteruelas, M.; Esteve-Zarzoso, B.; Mas, A.; Canals, J.M.; Zamora, F. Oenological consequences of sequential inoculation with non-Saccharomyces yeasts (Torulaspora delbrueckii or Metschnikowia pulcherrima) and Saccharomyces ceresviaie in base wine for sparkling wine production. Eur. Food Technol. 2015, 240, 999-1012. [CrossRef]

30. Ciani, M.; Maccarelli, F. Oenological properties of non-Saccharomyces yeasts associated with wine-making. World J. Microbiol. Biotechnol. 1998, 14, 199-203. [CrossRef]

31. Sadineni, V.; Kondapalli, N.; Obulam, V.S.R. Effect of co-fermentation with Saccharomyces cerevisiae and Torulaspora delbrueckii or Metschnikowia pulcherrima on the aroma and sensory properties of mango wine. Ann. Microbiol. 2012, 62, 1353-1360. [CrossRef]

32. Berry, D.R.; Slaughter, J.C. Alcoholic Beverage Fermentations. In Fermented Beverage Production, 2nd ed.; Lea, A.G.H., Piggott, J.R., Eds.; Kluwer Academic: New York, NY, USA, 2003; pp. 25-29, ISBN 978-0-306-47705-5.

33. Swiegers, J.H.; Bartowsky, E.J.; Henschke, P.A.; Pretoriu, I.S. Yeast and bacterial modulation of wine aroma and flavour. Aust. J. Grape Wine Res. 2005, 11, 139-173. [CrossRef] 
34. De Benedictis, M.; Bleve, G.; Grieco, F.; Tristian, M.; Tufariello, M.; Grieco, F. An optimized procedure for the enological selection of non-Saccharomyces starter cultures. Anton. Leeuw. 2011, 99, 189-200. [CrossRef] [PubMed]

35. Azzolini, M.; Tosi, E.; Lorenzini, M.; Finato, F.; Zapparoli, G. Contribution to the aroma of white wines by controlled Torulaspora delbrueckii cultures in association with Saccharomyces cerevisiae. World J. Microbiol. Biotechnol. 2015, 31, 277-293. [CrossRef] [PubMed]

36. Liu, S.Q.; Pilone, G.J. An overview of formation and roles of acetaldehyde in winemaking with emphasis on microbiological implications. Int. J. Food Sci. Technol. 2000, 35, 49-61. [CrossRef]

37. López, R.; Aznar, M.; Cacho, J.; Ferreira, V. Determination of minor and trace volatile compounds in wine by solid-phase extraction and gas chromatography with mass spectrometric detection. J. Chromatogr. A 2002, 966, 167-177. [CrossRef]

(C) 2018 by the authors. Licensee MDPI, Basel, Switzerland. This article is an open access article distributed under the terms and conditions of the Creative Commons Attribution (CC BY) license (http://creativecommons.org/licenses/by/4.0/). 